\title{
Comparison of AMSR-2 wind speed and sea surface temperature with moored buoy observations over the Northern Indian Ocean
}

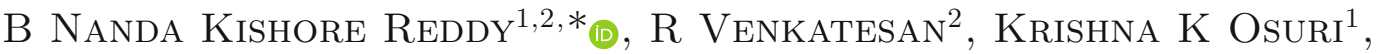 \\ Simi Mathew ${ }^{2}$, Jagadeesh Kadiyam ${ }^{3}$ and K Jossia Joseph ${ }^{2}$ \\ ${ }^{1}$ Department of Earth and Atmospheric Sciences, NIT Rourkela, Rourkela 769 008, India. \\ ${ }^{2}$ National Institute of Ocean Technology (NIOT), Chennai 600 100, India. \\ ${ }^{3}$ Indian Institute of Technology, Indore 453 552, India. \\ *Corresponding author. e-mail: nandu.eng@gmail.com
}

MS received 29 June 2016; revised 9 June 2017; accepted 12 June 2017; published online 14 February 2018

The Northern Indian Ocean (NIO) is unique due to seasonal reversal of wind patterns, the formation of vortices and eddies which make satellite observations arduous. The veracity of sea surface wind (SSW) and sea surface temperature (SST) products of sun-synchronous AMSR-2 satellite are compared with high-temporal moored buoy observations over the NIO. The two year-long (2013-2014) comparisons reveal that the root-mean-square-error (RMSE) of AMSR-2 SST and SSW is $<0.4^{\circ} \mathrm{C}$ and $<1.5 \mathrm{~ms}^{-1}$, respectively, which are within the error range prescribed for the AMSR-2 satellite $\left( \pm 0.8^{\circ} \mathrm{C}, \pm 1.5 \mathrm{~ms}^{-1}\right)$. The SST-wind relation is analyzed using data both from the buoy and satellite. As a result, the lowSST is associated with low-wind condition (positive slope) in the northern part of the Bay of Bengal (BoB), while low SST values are associated with high wind conditions (negative slope) over the southern BoB. Moreover, the AMSR-2 displayed larger slope for SST-wind relation and could be mainly due to overestimation of SST and underestimation of wind as compared to the buoy. The AMSR-2 SSW exhibited higher error during post-monsoon followed by monsoon season and could be attributed to the high wind conditions associated with intense oceanic vortices. The study suggests that the AMSR-2 products are reliable and can be used in tropical air-sea interactions, meso-scale features, and weather and climate studies.

Keywords. AMSR-2; SST; sea surface wind speed; moored buoys; Northern Indian Ocean.

\section{Introduction}

The Indian climate is affected by the neighbouring oceans, particularly the Bay of Bengal (BoB) and Arabian Sea (AS), hereafter called as the Northern Indian Ocean (NIO). In the tropics, the surface parameters such as sea surface temperature (SST) and sea surface wind speed (SSW) impact air-sea interactions. SST is an important and the potential physical parameter used for understanding the climate change and weather forecasting (e.g., Xie et al. 2002; Sutton and Hodson 2003; Latif et al. 2004; Dong et al. 2006). The NIO has peculiar water properties, physical characteristics and variable features where the wind circulation pattern is forced by the seasonal reversing of monsoon 
system. This makes the NIO as a challenging region for measuring both wind speed and SST from insitu observations. However, under 'Ocean Moored buoy Network for Northern Indian Ocean (OMNI)' program, the National Institute of Ocean Technology (NIOT), Chennai deployed good network of instrumented moored buoys over the NIO basin. These in-situ observations provide high temporal data at moored buoy (fixed) location (Eulerian platform) with a determined time interval. However, these observations are precise and not everywhere. Though, this data do not provide spatial variations of the fields, they address the observed temporal variability of surface fields on several time scales and can also be useful to validate model outputs, remote sensing data, etc.

As in-situ observations are sparse over the oceans, satellites became a major source for high temporal and spatial observations. Earlier Indian satellite IRS-P4 was the first oceanographic satellite, which provided the oceanographic parameters like SST, wind speed, integrated water vapor and cloud liquid water, etc. (Sharma et al. 2002). Bhat et al. (2004) validated the derived products of Tropical Rainfall Measuring Mission (TRMM) Microwave Imager (TMI) satellite with the Indian moored buoys data over the NIO basin. He found that the root mean square difference (RMSD) of SST is $0.5^{\circ} \mathrm{C}$ in the central $\mathrm{BoB}$ and $0.7^{\circ} \mathrm{C}$ in the northern BoB. Parekh et al. (2007) also demonstrated the similar analysis of surface winds and SST with the two space-borne sensors TRMM-TMI and multi-frequency scanning microwave radiometer (MSMR) with the direct measurements of NIO moored buoys.

The Advanced Microwave Scanning Radiometer (AMSR-2) is the operational microwave radiometer which provides the global coverage of data. It was launched by the Global Change Observation Mission - Water (GCOM-W) satellite developed by Japan Aerospace Exploration Agency (JAXA) on May 18, 2012, to monitor the global water and energy circulation. The GCOM (Global Change Observation Mission) is a series of satellite programmes (GCOM-W1, GCOM-W2 and GCOM-W3) to measure the persistent observations over the global ocean in a continuous manner. AMSR-2 is situated at an altitude of $700 \mathrm{~km}$ and its footprints (swath width) covers more than $1420 \mathrm{~km}$ radius. As the AMSR-2 is a microwave sensor, it is capable to operate in all weather conditions and provides continuous data, which will be helpful to understand the desperate situations that occur in real time scenario. Availability of AMSR-2 low frequencies (6.93 and $10.65 \mathrm{GHz}$ ) is used for retrieval of sea surface wind (SSW) and SST even under the cloudy conditions. The microwave radiometer has many advantages in measuring geophysical parameters related to water over the earth, such as observing various phases of water, viz., water vapour, cloud liquid water, precipitation, sea surface temperature, sea surface wind, snow depth, soil moisture and sea ice concentration.

Tomita et al. (2015) validated AMSR-2 SST and SSW over the Kuroshio extension region and exhibited satisfactory accuracy of the data. Gentemann and Hilburn (2015) also studied the overall quality of AMSR-2 data and demonstrated that SST bias and uncertainty has small seasonal dependency and could be related to the seasonal shift in the wind pattern. Hilburn and Smith (2013) validated AMSR-2 data over the Atlantic and Pacific Oceans and inferred that the data are in good agreement with available buoy observations and other microwave satellites. However, such validation over the NIO basin is limited.

Therefore, in the present study, we have made an attempt to compare the AMSR-2 SST and SSW fields, which are foremost for the air-sea interaction processes against the high temporal, in-situ measurements from five moored buoys, viz., three buoys in the BoB and two buoys in the AS region.

\section{Data and methodology}

\subsection{Moored buoy observations}

The five buoys deployed by the NIOT (National Institute of Ocean Technology) measure nearsurface mid-ocean parameters and sub-surface oceanographic parameters. The NIOT buoys have a suite of sensors which measure air pressure, temperature, humidity, rainfall, wind speed (sea surface wind) and direction, SST, shortwave radiation, long wave radiation, conductivity, ocean current speed and direction at one-hour interval. Following the objective of the study, the quality checks were conducted for SST and wind speed parameters. The SST is measured at a depth of $1 \mathrm{~m}$ (bulk temperatures) and no depth corrections were applied to the SST. The wind sensor which is at a height of $3 \mathrm{~m}$ from the sea surface measures the wind speed. In addition to the NIOT buoys, RAMA (Research Moored Array for African-Asian-Australian Monsoon Analysis and Prediction) buoys and WHOI 


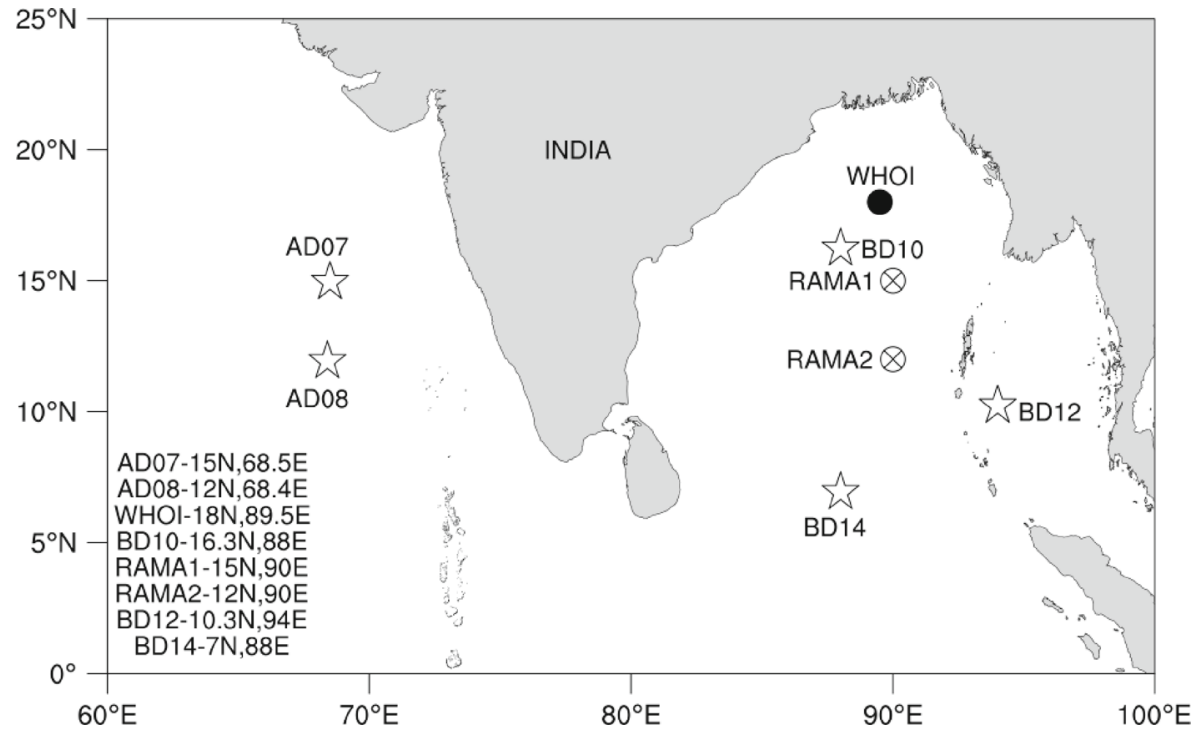

Figure 1. Location of moored buoys in the North Indian Ocean. Latitude and longitude of each buoy is mentioned in the lower left corner of the figure. Star symbol indicates NIOT buoys, cross-with-circle indicates RAMA (Research Moored Array for African-Asian-Australian Monsoon Analysis and Prediction) buoys and filled circle indicates WHOI (Woods Hole Oceanographic Institution) buoy.

(Woods Hole Oceanographic Institution) buoys are also used in the analysis. The locations (latitude and longitude) of all the buoys are presented in figure 1 .

\subsection{AMSR-2 product}

The AMSR-2 3-day average data products (version 7.2 ) of $0.25^{\circ} \times 0.25^{\circ}$ global resolution obtained online from www.remss.com/missions/amsre, have been considered for this study and is widely used by various research groups to validate over different parts of the globe (Hilburn and Smith 2013; Gentemann and Hilburn 2015). It is to be noted that the daily product of AMSR-2, i.e., ascending and descending passes has data gaps. The AMSR-2 measures the SSW in two different frequencies, i.e., SSW-LF (low frequency) and SSW-MF (medium frequency). The SSW-LF is less affected by rain and the atmosphere than SSW-MF. SSW-MF is little noisier when compared to the SSW-LF (http:// www.remss.com/missions/amsr). In this study, we used the AMSR-2 SSW-LF data to compare with the moored buoy observations.

The AMSR-2 satellite has the distinct, prescribed accuracies (release accuracy and standard accuracy) for the standard products. The release accuracy is defined as root mean square error (RMSE). The comparison of AMSR-2 with moored buoy observations helps to confirm whether it is in consigned accuracy or not over the NIO region.
Table 1 provides the resolution and accuracy of moored buoys (Venkatesan et al. 2013) and AMSR2 satellite parameters (Kachi et al. 2014).

As AMSR-2 is a 3-day moving average gridded product, the 1-hr buoy observations are converted into 3-day moving average for homogeneous comparison. The AMSR-2 measures the wind speed at a height of $10 \mathrm{~m}$ from mean sea level. The logarithmic wind law, consistent with Singh et al. (2013), is used to transform the $3-\mathrm{m}$ wind speed to $10-\mathrm{m}$ winds. In the above logarithmic wind law, we have not considered the atmospheric boundary layer. There is a discontinuity in moored buoy observations and can be partly attributed to the lack of ship time, sensor failures in the presence of oceanic vortices (for example, depressions, cyclones, etc.), fishing activities in the nearby buoys and weather conditions over the ocean, etc. The data gaps shown in table 2 during 2013-2014 can be linked to the above-mentioned reasons. Therefore, the statistical analysis is conducted with coexisted points of AMSR-2 and buoy data.

\section{Results}

The SST time series of AMSR-2 is compared with the buoy observations at locations shown in figure 1. The total data pairs used for this study is 1691. The analysis of all the datasets over the NIO suggested that AMSR-2 SST is 
Table 1. SST $\left({ }^{\circ} \mathrm{C}\right)$ and wind speed $\left(\mathrm{ms}^{-1}\right)$ specifications of NIOT moored buoy sensors and AMSR-2.

\begin{tabular}{|c|c|c|c|c|}
\hline $\begin{array}{l}\text { Moored buoy sensors } \\
\text { Parameter }\end{array}$ & Sensor type/make & Sensor resolution & Sensor accuracy & Sensor range \\
\hline $\begin{array}{l}\text { NIOT buoy SST } \\
\text { NIOT buoy wind speed } \\
\text { AMSR-2 satellite }\end{array}$ & $\begin{array}{l}\text { Thermistor/Seabird Micro-CAT SBE37 } \\
\text { Vane + flux gate compass/Lambrecht }\end{array}$ & $\begin{array}{l}0.0001^{\circ} \mathrm{C} \\
0.1 \mathrm{~ms}^{-1}\end{array}$ & $\begin{array}{l}0.002^{\circ} \mathrm{C} \\
\pm 2 \%\end{array}$ & $\begin{array}{l}-5-35^{\circ} \mathrm{C} \\
0-35 \mathrm{~ms}^{-1}\end{array}$ \\
\hline Parameter & Sensor & Spatial resolution & Accuracy & Range \\
\hline $\begin{array}{l}\text { AMSR-2 SST } \\
\text { AMSR-2 SSW }\end{array}$ & $\begin{array}{l}\text { Microwave radiometer } \\
\text { Microwave radiometer }\end{array}$ & $\begin{array}{l}0.25^{\circ} \times 0.25^{\circ} \\
0.25^{\circ} \times 0.25^{\circ}\end{array}$ & $\begin{array}{l}\left. \pm 0.8^{\circ} \mathrm{C} \text { (released }\right) \\
\pm 1.5 \mathrm{~ms}^{-1}(\text { released })\end{array}$ & $\begin{array}{l}-2-35^{\circ} \mathrm{C} \\
0-30 \mathrm{~ms}^{-1}\end{array}$ \\
\hline
\end{tabular}

Table 2. Total data gaps (in days) of individual moored buoys during 2013-2014.

\begin{tabular}{lcr}
\hline $\begin{array}{l}\text { Buoy } \\
\text { ID }\end{array}$ & $\begin{array}{c}\text { SST } \\
\text { (days) }\end{array}$ & $\begin{array}{r}\text { SSW } \\
\text { (days) }\end{array}$ \\
\hline AD07 & 390 & 224 \\
AD08 & 449 & 193 \\
BD10 & 327 & 102 \\
BD12 & 349 & 0 \\
BD14 & 348 & 151 \\
\hline
\end{tabular}

highly correlated (0.95) with a bias of $0.09^{\circ} \mathrm{C}$ and RMSE of $0.38^{\circ} \mathrm{C}$ with buoy observations. Overall time series analysis indicates that the AMSR-2 overestimates the maximum SSTs and underestimates minimum SSTs when compared to that of the buoy (figure 2). It should be noted that buoy provides a distinct signal of extreme weather events, i.e., tropical cyclones. AD07 and AD08 buoys showed a clear indication of the passage of TC Nanauk (June 2014; indicated by an arrow in figure $2 \mathrm{a}, \mathrm{b})$ through SST variations. AD07 (AD08) buoys show an SST drop of $\sim 2.4^{\circ} \mathrm{C}\left(\sim 1^{\circ} \mathrm{C}\right)$. SST drop is calculated as the difference between minimum and maximum SST within the TC period. The SST drop is a function of the proximity of the TC to the buoy. For example, the AD07 buoy which is $55 \mathrm{~km}$ apart from TC Nanauk showed a higher SST drop and AD08 buoy which is $\sim 388 \mathrm{~km}$ away exhibited a less SST drop. In case of AMSR-2, there is a data gap in both AD07 and AD08 locations during this TC which highlights the limitation of microwave radiometer under heavy rain and high wind $\left(>20 \mathrm{~ms}^{-1}\right)$ conditions (figure $\left.2 \mathrm{a}, \mathrm{b}\right)$ (retrieval algorithm report 2013; available at http://suzaku. eorc.jaxa.jp/GCOM_W/data/doc/NDX-120015A. pdf). Though, there is a data gap in AMSR-2 SST during the TC event, there is a significant SST difference before and after the TC pass. The presence/impact of TC Nanauk at AD07 (AD08) locations is noticed with an SST difference of $\sim 4.8^{\circ} \mathrm{C}\left(\sim 2.5^{\circ} \mathrm{C}\right)$. Considering another example, over the BoB, a recent TC Hudhud (9-12 October 2014) passed in the vicinity of BD10. In case of TC Hudhud, BD10 showed an SST drop of $\sim 3^{\circ} \mathrm{C}$, while AMSR-2 exhibited SST difference of $\sim 2.1^{\circ} \mathrm{C}\left(30.3^{\circ} \mathrm{C}\right.$ before genesis, i.e., 8 October 2014 and $28.2^{\circ} \mathrm{C}$ after the event, i.e., 13 October 2014) (indicated by an arrow in figure $2 \mathrm{c}$ ).

The qualitative time series comparison is supported by the quantitative error statistics, which are provided in figure $2\left(\mathrm{a}^{\prime}-\mathrm{e}^{\prime}\right)$. It infers that the AMSR-2 is underestimating the SST (by approximately $-0.09^{\circ} \mathrm{C}$ ) over the AS and overestimating over the BoB (by $\sim 0.1^{\circ} \mathrm{C}$ ). The mean RMSE of AMSR-2 SST over the AS is $\sim 0.35^{\circ} \mathrm{C}$ and highly correlated (0.95) with the buoy observations. Similar error statistics are obtained for the BoB with RMSE of $\sim 0.3^{\circ} \mathrm{C}$ and correlation is 0.95 , respectively. These error statistics support the AMSR-2 observations for its use over the NIO region to understand the different processes like weather prediction, ocean forecast and coastal applications, etc.

\subsection{Wind speed variations over NIO}

In addition to the SST parameter, the above analysis is also carried out for AMSR-2 wind speed, which is one of the sources for SST alterations. The time series and statistical analysis shown in figure 3 help us to understand the quality of AMSR-2 data in the NIO region. The mean RMSE of AMSR-2 wind speed is $1.21 \mathrm{~ms}^{-1}$. The overall correlation is 0.9 with a bias of $0.26 \mathrm{~ms}^{-1}$. This highlight that the quality of AMSR-2 wind speed is within the prescribed error range (i.e., $1.5 \mathrm{~ms}^{-1}$ ) over the NIO region. AMSR-2 displays useful information/signals about the most destructive parameter, the wind speed, of the oceanic vortices like in SST. 


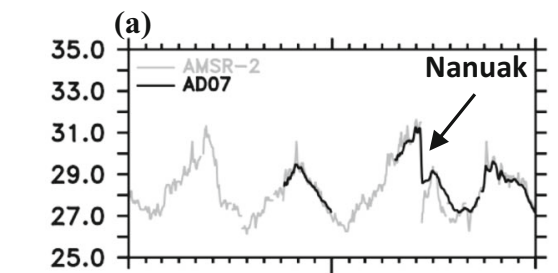

(b)

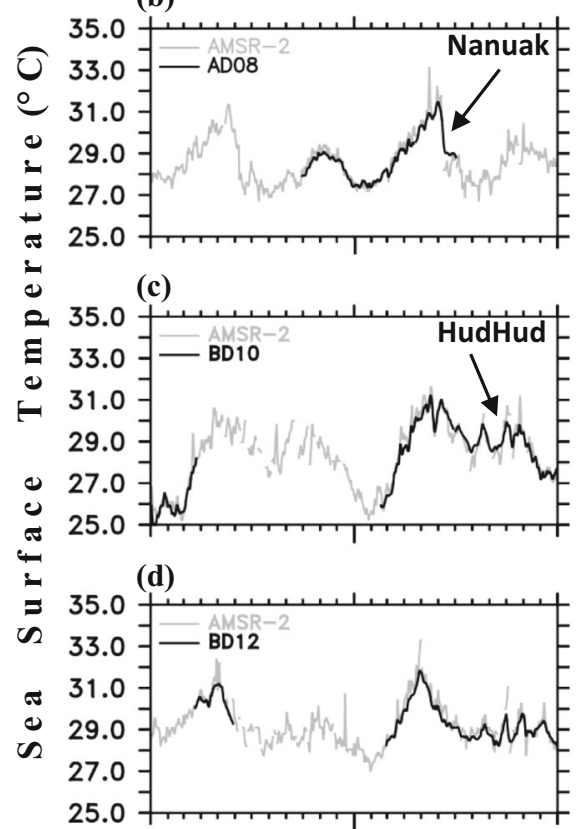

(e)

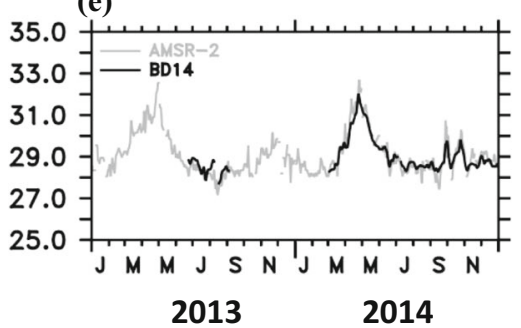

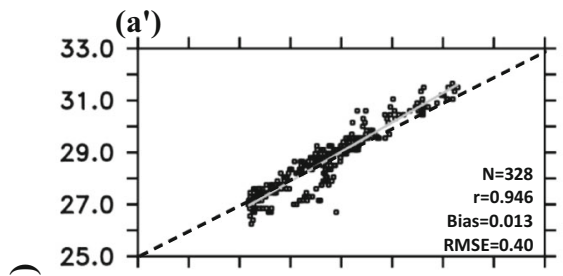

(b')
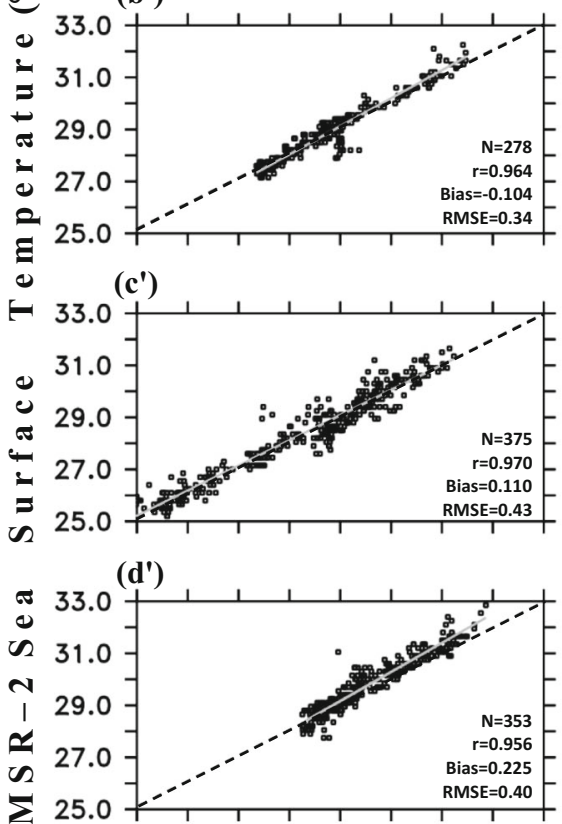

$\left(\mathrm{e}^{\prime}\right)$

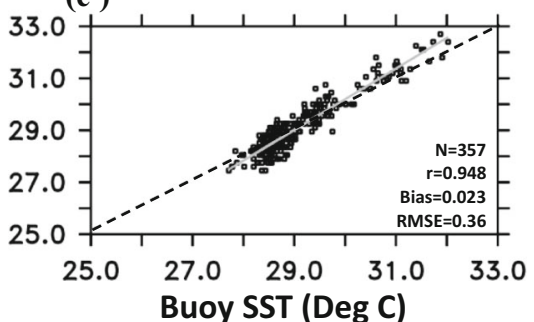

Figure 2. Statistical analysis of SST $\left({ }^{\circ} \mathrm{C}\right)$ at moored buoy locations for the period 2013-2014 (a-e) time series comparison and $\left(\mathbf{a}^{\prime}-\mathbf{e}^{\prime}\right)$ scatter plots corresponding to (a-e) respectively, between buoy and AMSR-2. Total number of data points, correlation, bias and RMSE of AMSR-2 SST with respect to buoy SST is given in $\left(\mathbf{a}^{\prime}-\mathbf{e}^{\prime}\right)$.

For example, BD10 location (figure 3c) exhibited the peak wind speed more than $\sim 23 \mathrm{~ms}^{-1}$ (11 October 2013) during the life span of very severe cyclonic storm 'Phailin' ( $\sim 7.5 \mathrm{~km}$ apart from the cyclone track; shown with an arrow in the figure 3c) in October, 2013. The AMSR-2 SSW is perceived with similar high winds, i.e., $>18 \mathrm{~ms}^{-1}$ on 12 October, 2013.

From figure $3\left(\mathrm{a}^{\prime}-\mathrm{e}^{\prime}\right)$, the statistical analysis of wind speed at different buoys indicated that the RMSE is $<1.5 \mathrm{~ms}^{-1}$ for all the moored buoy locations and satisfies the release accuracy of AMSR-2 wind speed (Imaoka et al. 2010). Slightly higher (but within the prescribed range i.e., $\pm 1.5 \mathrm{~ms}^{-1}$ )
RMSE at BD10 location may be due to the fact that this region is active for oceanic vortices such as monsoon depressions, intense TCs that associate with high wind conditions (for example, the TC Phailin). The mean statistics indicate that wind speed is overestimating over AS and underestimating over BoB by about $0.1 \mathrm{~ms}^{-1}$ and $-0.2 \mathrm{~ms}^{-1}$, respectively. The mean RMSE of wind speed over the $\mathrm{AS}$ and $\mathrm{BoB}$ are of about $1 \mathrm{~ms}^{-1}$ and $1.3 \mathrm{~ms}^{-1}$, respectively, and is within the released accuracy. AMSR-2 wind speed is in the same phase with that of buoy showing high positive correlation of $0.93(\mathrm{AS})$ and $0.89(\mathrm{BoB})$, respectively. 


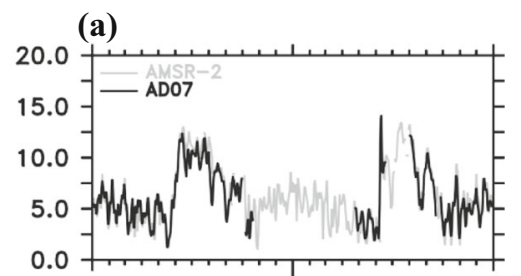

(b)

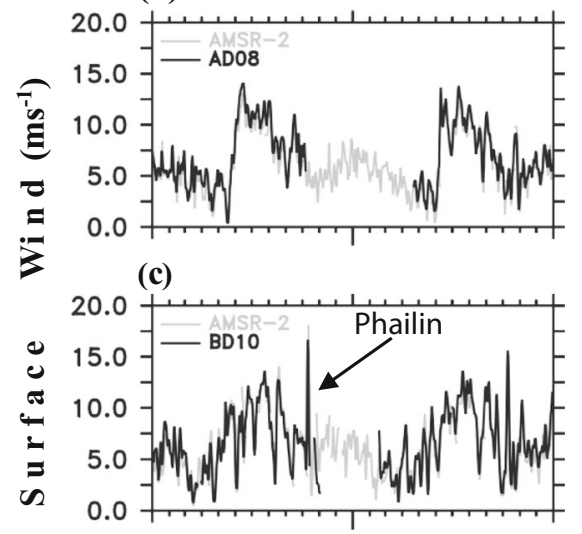

(d)
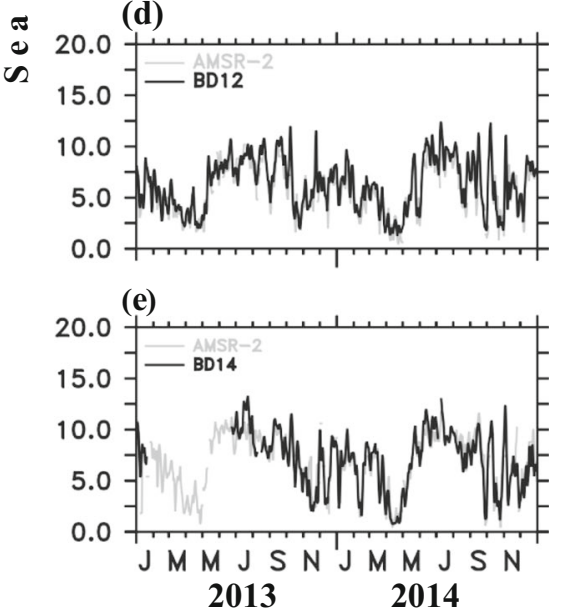
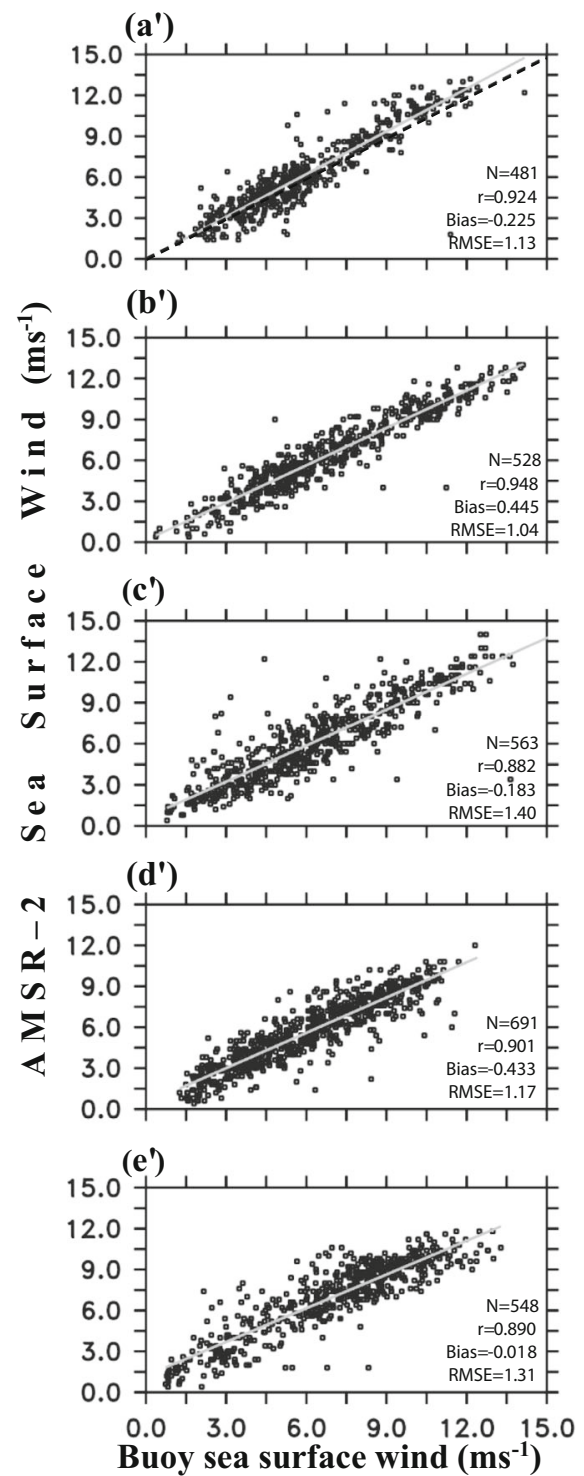

Figure 3. Same as figure 2, but for wind speed $\left(\mathrm{ms}^{-1}\right)$.

\subsubsection{AMSR-2 SSW error statistics on different conditions}

The analysis is extended to understand the quality of AMSR-2 wind speed in a constructive manner, it is required to discern the range of wind speeds into different categories such as low $\left(\leq 5 \mathrm{~ms}^{-1}\right)$, medium $\left(5-10 \mathrm{~ms}^{-1}\right)$ and high $\left(\geq 10 \mathrm{~ms}^{-1}\right)$ wind conditions. Table 3 provides the error statistics for these three categories of AMSR-2 wind speed with respect to buoy data. The overall statistics revealed that AMSR-2 wind speed is highly reliable for low and medium wind conditions with RMSE of $0.7 \mathrm{~ms}^{-1}$ and correlation of 0.8. However, wind data are less reliable under high wind conditions with RMSE of
$1 \mathrm{~ms}^{-1}$ and correlation of 0.4 and is attributed to the limitation of the AMSR-2 instrument under high wind conditions $\left(<30 \mathrm{~ms}^{-1}\right)$ and heavy precipitation (retrieval algorithm report 2013; available at http://suzaku.http://suzaku.eorc.jaxa.jp/ eorc.jaxa.jp/GCOM_W/data/doc/NDX-120015A. pdf). It could be due to differences in both the datasets due to 3-day running average. Such high wind and precipitation conditions occur normally in the presence of deep convective system such as TCs, monsoon depressions, etc. At BD14 and BD10 locations (i.e., in the southern and central BoB), the AMSR-2 is exhibited with higher RMSE $\sim 1.17 \mathrm{~ms}^{-1}$ and $1.29 \mathrm{~ms}^{-1}$ and less correlation of 0.24 and 0.47 for high wind conditions. 
Table 3. Error statistics of AMSR-2 wind speed at different thresholds $\left(\mathrm{ms}^{-1}\right)$ during 2013-2014.

\begin{tabular}{lcrccc}
\hline Location & $\begin{array}{c}\text { Wind speed } \\
\text { range }\left(\mathrm{ms}^{-1}\right)\end{array}$ & $\begin{array}{r}\text { N (no. of } \\
\text { datasets })\end{array}$ & $\begin{array}{c}\text { Bias } \\
\left(\mathrm{ms}^{-1}\right)\end{array}$ & $\begin{array}{c}\text { RMSE } \\
\left(\mathrm{ms}^{-1}\right)\end{array}$ & $\begin{array}{c}\text { Correlation } \\
(r)\end{array}$ \\
\hline AD07 & $\leq 5$ & 159 & -0.12 & 0.61 & 0.80 \\
& $5-10$ & 192 & 0.28 & 0.72 & 0.86 \\
AD08 & $\geq 10$ & 51 & 0.47 & 0.99 & 0.46 \\
& $\leq 5$ & 138 & -0.37 & 0.75 & 0.83 \\
& $5-10$ & 220 & -0.28 & 0.66 & 0.90 \\
BD10 & $\geq 10$ & 85 & -0.66 & 0.82 & 0.87 \\
& $\leq 5$ & 171 & -0.12 & 0.71 & 0.78 \\
BD12 & $5-10$ & 236 & 0.21 & 0.79 & 0.81 \\
& $\geq 10$ & 58 & -0.37 & 1.29 & 0.47 \\
& $\leq 5$ & 233 & -0.34 & 0.76 & 0.78 \\
BD14 & $5-10$ & 334 & -0.44 & 0.81 & 0.81 \\
& $\geq 10$ & 14 & -0.29 & 0.52 & 0.008 \\
& $\leq 5$ & 114 & 0.25 & 0.70 & 0.85 \\
& $5-10$ & 291 & -0.009 & 0.79 & 0.77 \\
\hline
\end{tabular}
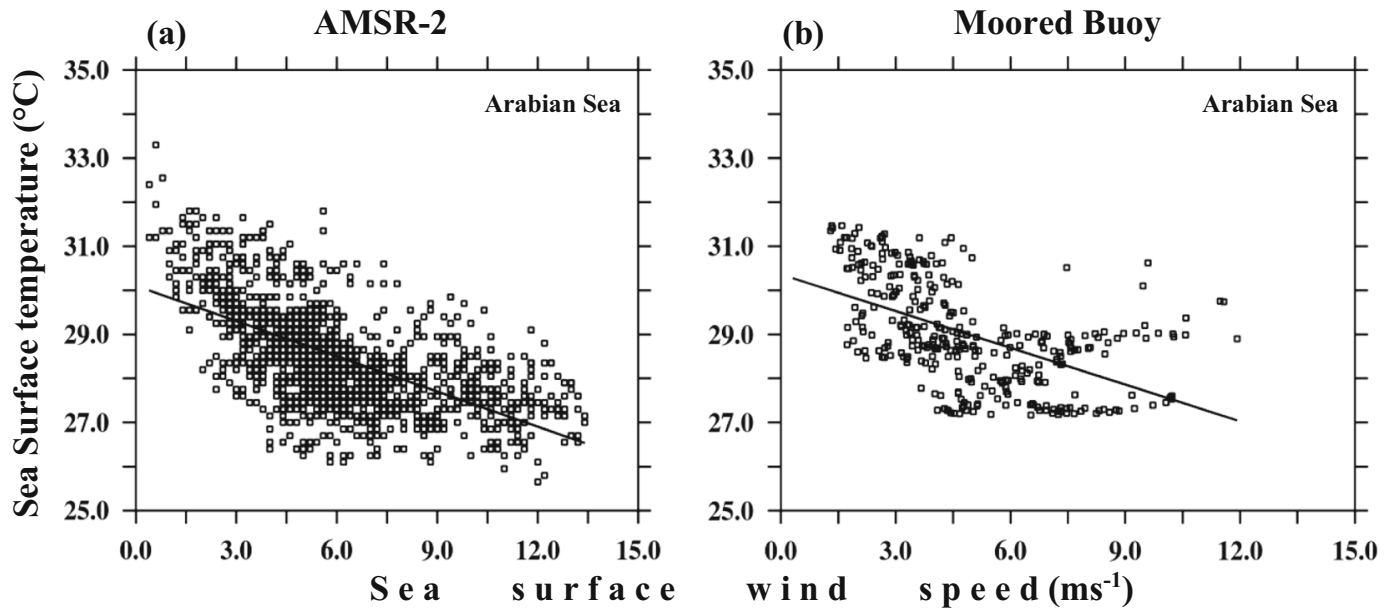

Figure 4. Relationship between $\operatorname{SST}\left({ }^{\circ} \mathrm{C}\right)$ and wind speed $\left(\mathrm{ms}^{-1}\right)$ for the period 2013-2014 for AMSR-2 satellite over (a) Arabian Sea and (b) with the moored buoys. Note that data of all buoys during the period are considered for this scatter plot.

\subsection{SST-wind relationship over NIO}

The study is further extended to understand the SST dependency (either subskin or bulk) on surface winds over the BoB and AS basins separately. This analysis will explore the possible conditions for SST changes in these basins with respect to wind changes. All the buoys during 2013-2014 are collectively used to analyze the relationship over the AS region. Likewise, the relationship is also obtained from the AMSR-2 data. Figure 4 shows that temperature decreases linearly with the increase in wind speed for satellite and moored buoy observations yielding a negative slope in the fitted line. A similar relationship is noticed at an individual buoy location also. Parekh and Sarkar (2009) conducted a similar study with the difference in temperature (subskin-bulk) vs. surface wind and revealed that variation of temperature with wind speed shows the similar behaviour as obtained in the present analysis.

Considering the $\mathrm{BoB}$, an interesting fact is noticed while comparing the wind speed variations with respect to the SST. In the northern BoB, the above-said relation is failed, while it is persisted over southern BoB. A well-known fact, in the northern $\mathrm{BoB}$ (considered as north of $16^{\circ} \mathrm{N}$ ) is that the freshwater discharge of major rivers such as 

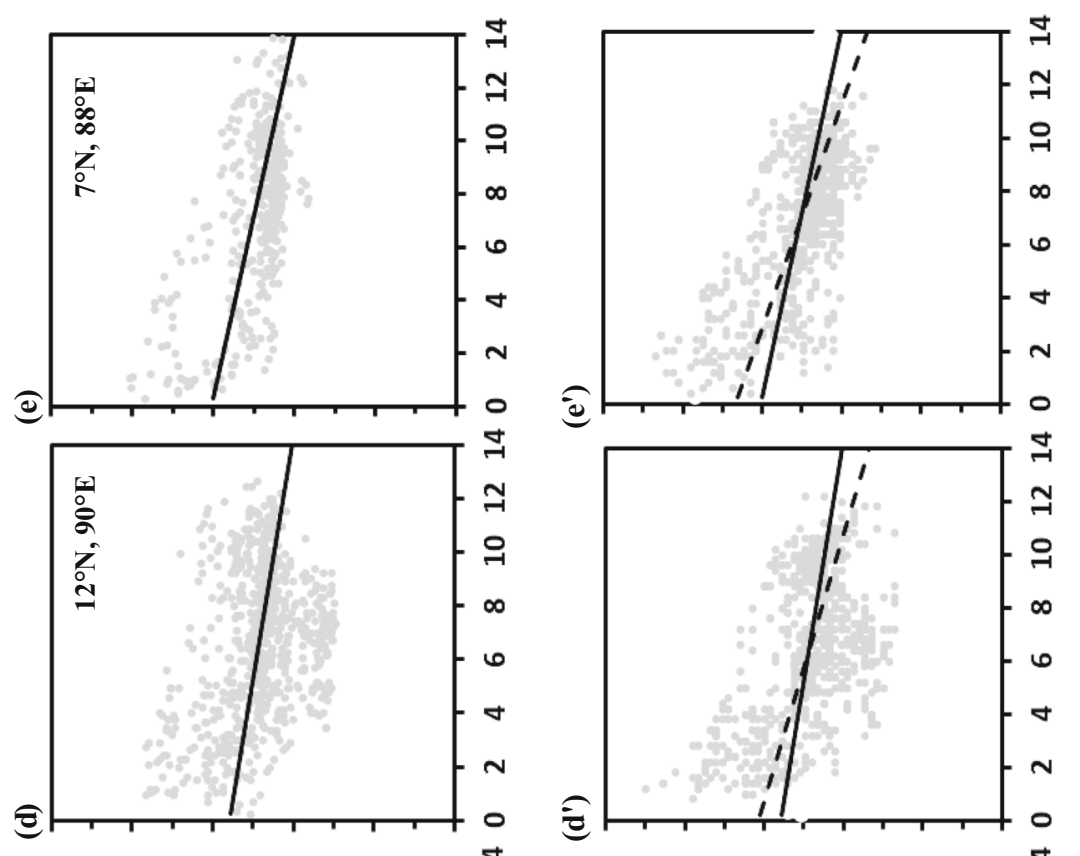

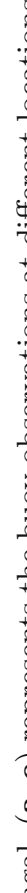

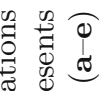

元
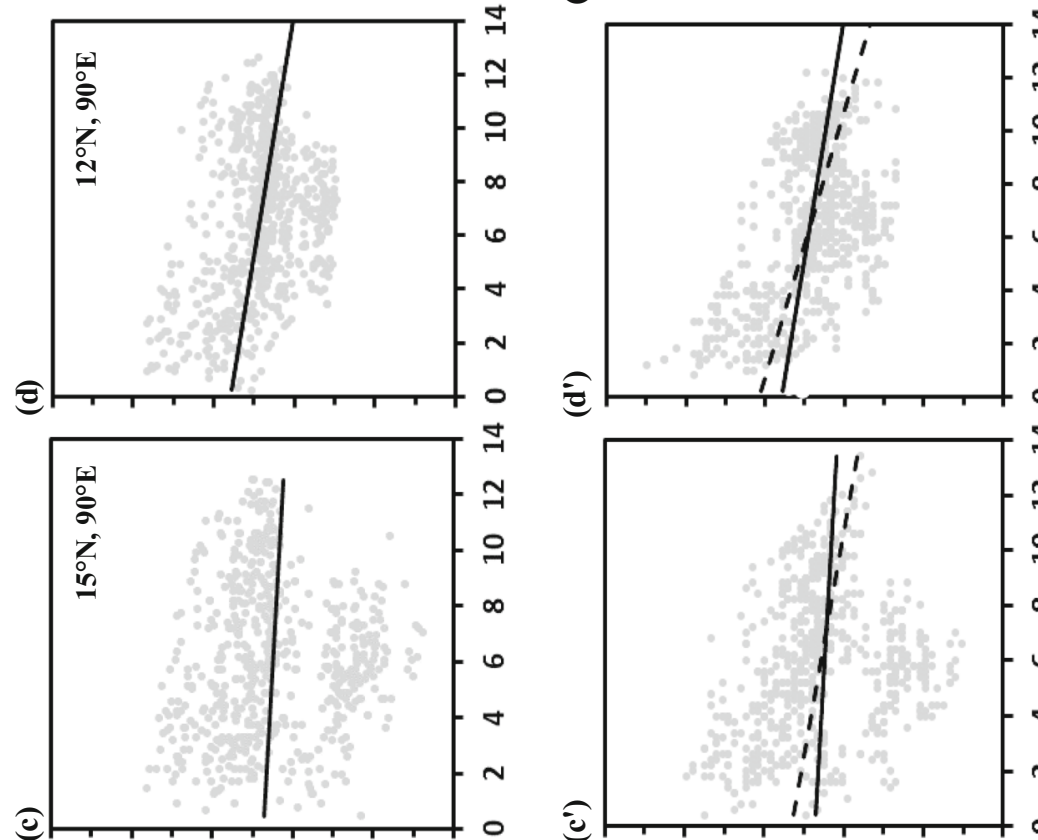

娄要

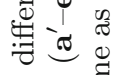

范

窎击

蛋

․․

용.

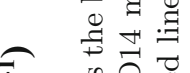

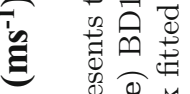

-

$\therefore$ वे

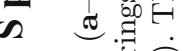

$\begin{array}{lll}\pi_{0} & 0 & 0 \\ \infty & 0 & \sigma\end{array}$

虫

=

$\div \quad$ ติ

3 गे

+ on

तै

- $\stackrel{2}{\circ}$ :

ช ㄱํㅇำ
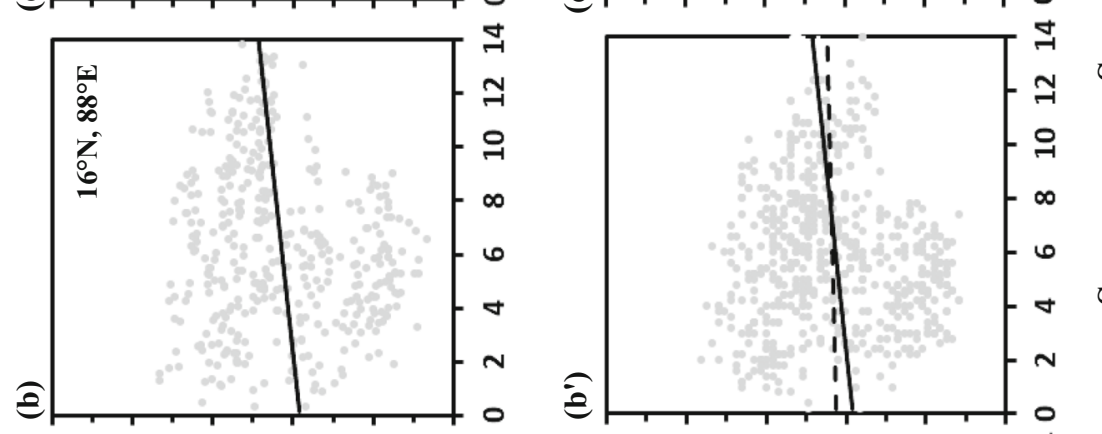

-

$=82$

के

국

क :

- द्व

(1) छ

की

品 ‘

궁
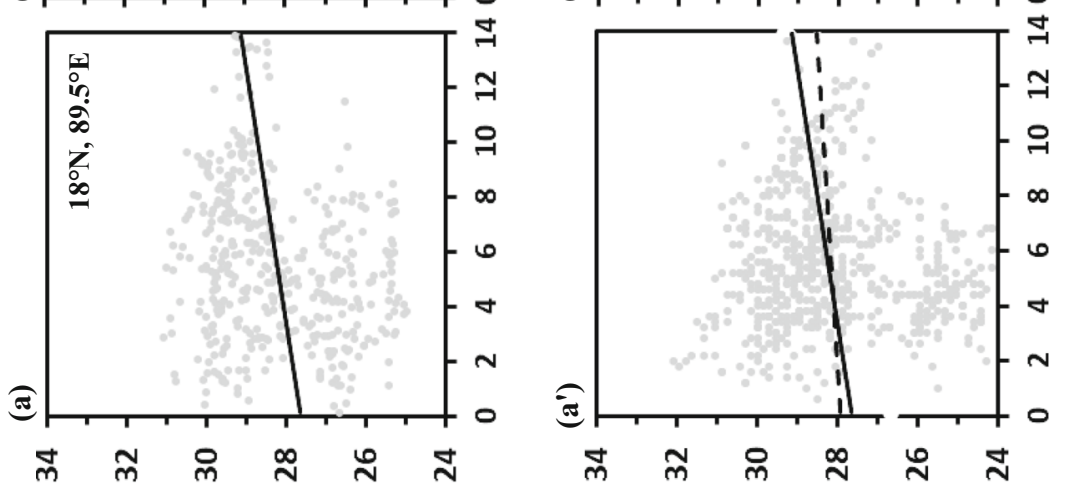

Oे क्षे

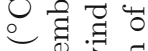

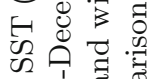

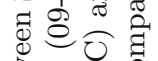

范告

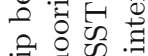

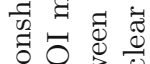

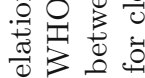

นิ ฮี ซ్

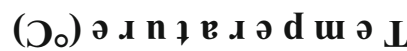

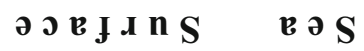

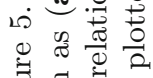

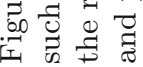


Table 4. Season-wise statistical analysis of SST/SSW of AMSR-2.

\begin{tabular}{lcccc}
\hline Season & $\begin{array}{c}\text { No. of data } \\
\text { points }\end{array}$ & Bias* & RMSE & Correlation \\
\hline Pre-monsoon (April-May) & $274 / 180$ & $0.303 /-0.016$ & $0.44 / 0.99$ & $0.88 / 0.91$ \\
Southwest monsoon (June-Sep) & $438 / 456$ & $0.1158 / 0.340$ & $0.42 / 1.19$ & $0.90 / 0.88$ \\
Post-monsoon (Oct-Nov) & $223 / 289$ & $0.1 /-0.17$ & $0.40 / 1.40$ & $0.82 / 0.82$ \\
\hline
\end{tabular}

*Positive (negative) bias indicates overestimation (underestimation) of AMSR-2 data.

the Ganges-Brahmaputra-Meghna and Irrawaddy rivers creates strong near surface halocline (Sengupta et al. 2016) leading to strong stratification. In contrast, due to lack of freshwater influx, higher saline waters are observed in the southern BoB (south of $16^{\circ} \mathrm{N}$ ) with less stratification. The annual climatology of surface salinity increases towards south (Chatterjee et al. 2012). The average surface salinity at $18^{\circ} \mathrm{N}$ latitude is $\sim 31.87 \mathrm{PSU}$ and at $7^{\circ} \mathrm{N}$ latitude is $33.94 \mathrm{PSU}$. It indicates decreased stratification from northern to southern BoB. This analysis is supported by a recent study by Neetu et al. (2012).

Therefore, the statistical analysis is conducted to understand the changes in the SST-wind relationship from northern $\mathrm{BoB}\left(>16^{\circ} \mathrm{N}\right.$; high stratification) to south $\mathrm{BoB}\left(<16^{\circ} \mathrm{N}\right.$; low stratification $)$. This analysis is carried out at five buoy locations such as WHOI mooring $\left(89.5^{\circ} \mathrm{E}, 18^{\circ} \mathrm{N}\right.$; Weller et al. 2016), RAMA moorings (at $15^{\circ} \mathrm{N}, 90^{\circ} \mathrm{E}$ and $12^{\circ} \mathrm{N}, 90^{\circ} \mathrm{E}$; NOAA, PMEL) and NIOT moorings (BD10 and BD14) (figure 1). In figure $5(\mathrm{a}-\mathrm{b})$, it can be clearly observed that the SST data is deviated to the lower values from the fitted line under low wind conditions over the northern BoB. In other words, the slope of the fitted line is positive. Such deviation is mild over central BoB (figure $5 \mathrm{c}$ ). Considering southern BoB (figure $5 \mathrm{~d}-\mathrm{e}$ ), the low wind conditions are associated with higher SST values and high wind conditions are associated with lower SST values, inferring a negative slope in the fitted line. It is also noted that the spread of data on either side of the fitted line is more in northern $\mathrm{BoB}$, while it is confined to the fitted line in southern BoB. On keen observation, it reveals that the slope of the fitted line is slowly changing in clockwise direction from northern BoB to southern BoB (figure 5), i.e., from positive slope to negative slope. The similar statistical analysis is done with the AMSR-2 data (figure $5 \mathrm{a}^{\prime}-\mathrm{e}^{\prime}$ ) at the corresponding locations as in figure $5(\mathrm{a}-\mathrm{e})$. Overall behaviour such as clockwise shifting of the fitted line of the AMSR-2 data is consistent with that of buoy observations at all the locations of the BoB. However, the fitted-line slope of the AMSR-2 data is relatively larger than that of the buoy fitted line. It infers that there is a large SST change for a small change in wind speed (slope $=\mathrm{SST} /$ wind speed) in AMSR-2 data. One of the reasons for the larger slope of AMSR-2 data could be mainly attributed to the positive bias (overestimation) of SST and negative bias (underestimation) of wind over the BoB.

The analysis is extended to understand the nature of SST-wind relation in different seasons, i.e., pre-monsoon (April-May), southwest monsoon (June-September) and post-monsoon (OctoberNovember) seasons. Note that this analysis is carried for 2014 as there are substantial data gaps in 2013. The season-wise error statistics presented in table 4 indicates the positive SST bias (overestimation) is associated with the negative bias (underestimation) of wind speed in pre- and post-monsoon seasons, while the overestimation of wind is associated with overestimation of SST during monsoon season. The RMSE of AMSR-2 wind speed is relatively higher during post-monsoon season followed by monsoon season and can be attributed to the high wind conditions prevailed due to the presence of intense oceanic vortices such as monsoon depressions and TCs. The AMSR-2 winds are highly correlated with that of buoy during pre-monsoon season than that of other two seasons.

\section{Conclusions}

The SST and wind speed derived from the AMSR2 is compared using five moored buoy observations in the Northern Indian Ocean (Bay of Bengal and Arabian Sea). The overall results revealed that the SST and wind speed is in good agreement with the buoy observations, within the released accuracy. The correlation, bias and RMSE of SST (wind speed $)$ are $\sim 0.95(\sim 0.90), \sim 0.09^{\circ} \mathrm{C}\left(\sim 0.26 \mathrm{~ms}^{-1}\right)$ and $\sim 0.38^{\circ} \mathrm{C}\left(\sim 1.21 \mathrm{~ms}^{-1}\right)$, respectively. Further analysis revealed that the AMSR-2 data is reliable in low and medium wind conditions with less 
RMSE $\left(\sim 0.7 \mathrm{~ms}^{-1}\right)$ and high correlation $(>0.8)$ when compared to that of high wind conditions.

The wind-SST relationship is evaluated separately over $\mathrm{AS}$ and $\mathrm{BoB}$ regions. The conventional relationship between wind and SST (i.e., temperature decreases with increased wind speed) is persisted over the AS. The SST-wind relation over the BoB may be influenced by the ocean surface stratification, which has a different character in northern and southern parts of $\mathrm{BoB}$. In the northern BoB, an opposite wind-SST relation (i.e., low wind conditions are with low SST) is noticed. There is a clockwise change in the fitted line (positive slope to negative slope) from northern to southern BoB. Though such relation is obtained from AMSR-2 data, the slope (SST/wind speed) of the fitted line is relatively larger than that of buoy observations. This could be because of overestimation in SST and underestimation in the wind. The AMSR-2 data during pre- and post-monsoon showed overestimation (underestimation) in SST (wind speed) and both the parameters are overestimated during monsoon season.

Therefore, the present analysis highlights that the quality of AMSR-2 SST and surface wind speed data over the NIO basin is acceptable and can be used in place of observations whenever required.

\section{Acknowledgements}

The authors gratefully acknowledge the financial support from the SERB (ECR/2016/ 001637), Department of Science \& Technology, Govt. of India. We thank Dr Wentz F J of Remote Sensing Systems for making the AMSR-2 SST and wind speed 3-day average product available on their website www.remss.com/missions/ amsre. Freeware Ferret and NCL are used in this study. The authors are also thankful to the Ministry of Earth Sciences (MoES), Govt. of India, for maintaining the moored buoy network over the NIO. The authors also thank the anonymous reviewers for their constructive and valuable suggestions that helped to improve the quality of the manuscript.

\section{References}

Bhat G S, Vecchi G A and Gadgil S 2004 Sea surface temperature of the Bay of Bengal derived from the TRMM Microwave Imager; J. Atmos. Ocean. Tech. 21 1283-1290.
Chatterjee A, Shankar D, Shenoi S S C, Reddy G V, Michael G S and Ravichandran M et al. 2012 A new atlas of temperature and salinity for the North Indian Ocean; J. Earth Syst. Sci. 121(3) 559-593.

Dong S, Gille S T, Sprintall J and Gentemann C 2006 Validation of Advanced Microwave Scanning Radiometer for the Earth Observing System (AMSR-E) sea surface temperature in the Southern Ocean; J. Geophys. Res. 111 C04002, https://doi.org/10.1029/2005JC002934.

Gentemann C L and Hilburn K A 2015 In situ validation of sea surface temperatures from the GCOM-W1 AMSR2 RSS calibrated brightness temperatures; J. Geophys. Res. 120 3567-3585.

Hilburn K and D K Smith 2013 Validation and early science from AMSR-2, AGU fall meeting, 2013, OS41A-1804, http://adsabs.harvard.edu/abs/ 2013AGUFMOS41A1804H.

Imaoka K, Kachi M, Kasahara M, Ito N, Nakagawa K and Oki T 2010 Instrument performance and calibration of AMSR-E and AMSR2; ISPRS. xxxviii, part 8.

Kachi M, Hori M, Maeda T and Imaoka K 2014 Status of validation of AMSR-2 on board the GCOM-W1 satellite; IEEE Geoscience and Remote Sensing Symposium, pp. 110-113, https://doi.org/10.1109/IGARSS.2014.6946368.

Latif M, Roeckner E, Botzet M, Esch M, Haak H, Hagemann S, Jungclaus J, Legutke S, Marsland S, Mikolajewicz U and Mitchell J 2004 Reconstructing, monitoring, and prediciting multidecadal-scale changes in the North Atlantic thermohaline circulation with sea surface temperature; J. Clim. 17 1605-1614.

Neetu S, Lengaigne M, Vincent E M, Vialard J, Madec G and Samson G et al. 2012 Influence of upper-ocean stratification on tropical cyclone-induced surface cooling in the Bay of Bengal; J. Geophys. Res.: Oceans 117(C12).

Parekh A and Sarkar A 2009 Co-variation in subskin-bulk temperature difference with environmental parameters in the north Indian Ocean Int. J. Remote Sens. 30 20492059.

Parekh A, Sharma R and Sarkar A 2007 A comparative assessment of sea surface temperature and surface wind speed over the Indian Ocean by TMI, MSMR, and ERA40; J. Atmos. Oceanic Tech. 24 1131-1142.

Sengupta D, Bharath Raj G N, Ravichandran M, Sree Lekha J and Papa F 2016 Near-surface salinity and stratification in the north Bay of Bengal from moored observations; Geophys. Res. Lett. 43(9) 4448-4456.

Sharma R, Babu K N, Mathur A K and Ali M M 2002 Identification of large-scale atmospheric and oceanic features from IRS-P4 multifrequency scanning microwave radiometer: Preliminary results; J. Atmos. Ocean. Tech. 19 1127-1134.

Singh P, Parekh A and Attada R 2013 Comparison of a simple logarithmic and equivalent neutral wind approaches for converting buoy-measured wind speed to the standard height: Special emphasis to North Indian Ocean; Theor. Appl. Climatol. 111(3) 455-463.

Sutton R T and Hodson D L 2003 Influence of the ocean on North Atlantic climate variability 1871-1999; J. Clim. 16 3296-3313.

Tomita H, Kawai Y, Cronin M F, Hihara T and Kubota M 2015 Validation of AMSR-2 sea surface wind and 
temperature over the Kuroshio Extension Region; SOLA 11 43-47, https://doi.org/10.2151/sola.2015-010.

Venkatesan R, Shamji V R, Latha G, Mathew S, Rao R R, Muthiah A and Atmanand M A 2013 In situ ocean subsurface time-series measurements from OMNI buoy network in the Bay of Bengal; Curr. Sci. 104(9) 11661177 .

Corresponding editor: D SHANKAR
Weller R A, Farrar J T, Buckley J, Mathew S, Venkatesan R and Lekha J S et al. 2016 Air-sea interaction in the Bay of Bengal; Oceanography 29(4) 28-37.

Xie S P, Annamalai H, Schott F A and McCreary Jr J P 2002 Structure and mechanisms of south Indian Ocean climate variability; J. Clim. 15 864-878. 